\title{
Dual-Mode Combustion Experiments with an Integrated Aeroramp-Injector/Plasma-Torch Igniter
}

\author{
Aristides M. Bonanos, $\underset{*}{-}$ Joseph A. Schetz, $\stackrel{\ddagger}{-}$ and Walter F. O’Brien $\stackrel{\neq}{ \pm}$ \\ Virginia Polytechnic Institute and State University, Blacksburg, Virginia 24060 \\ and \\ Christopher P. Goyne $\underline{\S}$ \\ University of Virginia, Charlottesville, Virginia 22904
}

DOI: $\underline{10.2514 / 1.28301}$

\begin{abstract}
Results from combustion experiments in a direct-connect supersonic combustor facility are presented. Successful ignition and sustained combustion of both hydrogen and ethylene fuels were achieved using an integrated aerorampinjector/plasma-torch igniter configuration. A Mach 2 nozzle was used to obtain flow simulating Mach $\approx 4$ flight conditions at $27 \mathrm{~km}$, at a total temperature of $1000 \mathrm{~K}$ and a static pressure of $42 \mathrm{kPa}$. Combustion was achieved at (global) equivalence ratios between 0.08 and 0.31 for hydrogen and 0.13 and 0.47 for ethylene, with corresponding maximum combustor pressure rises of about a factor of 4.0. One-dimensional performance analysis of the test data indicates combustion efficiencies as high as $\mathbf{7 5 \%}$ for both fuels, in the leanest conditions tested. Off-design flight conditions were tested by varying the freestream air total temperature. Supersonic combustion was achieved at total temperatures as low as $530 \mathrm{~K}$ with hydrogen and $680 \mathrm{~K}$ with ethylene.
\end{abstract}

\section{Nomenclature}

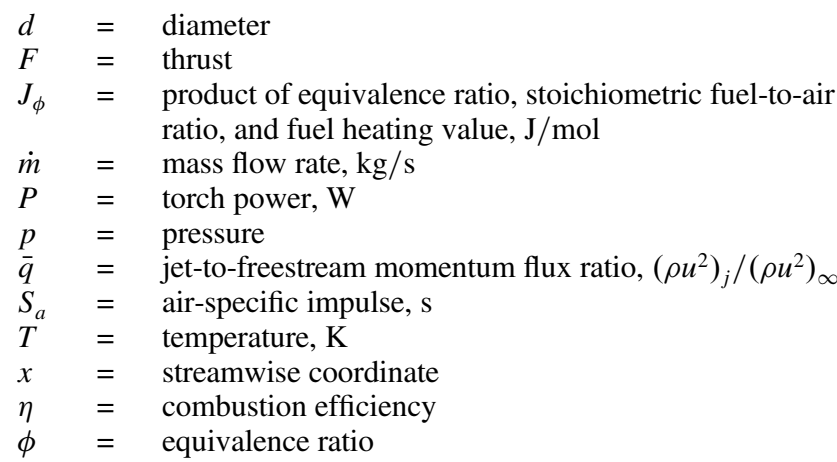

Subscripts

eq $=$ equivalent

$j=$ jet

$o \quad=\quad$ stagnation condition

$\infty=$ freestream condition

\section{Introduction}

$\mathbf{S}$ UPERSONIC combustion inherently involves difficulties not present in other combustion systems. The high flow velocities in the combustor, which can reach several thousand meters per second,

Received 10 October 2006; revision received 21 August 2007; accepted for publication 8 September 2007. Copyright (C) 2007 by the authors. Published by the American Institute of Aeronautics and Astronautics, Inc., with permission. Copies of this paper may be made for personal or internal use, on condition that the copier pay the $\$ 10.00$ per-copy fee to the Copyright Clearance Center, Inc., 222 Rosewood Drive, Danvers, MA 01923; include the code $0748-4658 / 08 \$ 10.00$ in correspondence with the CCC.

${ }^{*}$ Graduate Research Assistant, Department of Aerospace and Ocean Engineering; presently Postdoctoral Scholar, Graduate Aeronautical Laboratories, California Institute of Technology, 1200 E. California Boulevard, MC 301-46, Pasadena, California 91125. Member AIAA.

${ }^{\dagger}$ Professor, Fred D. Durham Chair, Department of Aerospace and Ocean Engineering. Fellow AIAA.

${ }^{\sharp}$ Professor, J. Bernard Jones Professor, Department of Aerospace and Ocean Engineering. Associate Fellow AIAA.

${ }^{\S}$ Research Assistant Professor, Department of Mechanical and Aerospace Engineering. Senior Member AIAA. cause extremely low fuel residence times. Therefore, there is a requirement for a fuel injection/ignition system with enhanced performance characteristics. Fuel-air mixing, flame holding, pressure losses, and thermal loading must all be considered for the successful design of a supersonic combustion ramjet (scramjet) engine. A practical system must induce rapid mixing while minimizing total pressure losses, without adverse effects on the flame holding capability or thermal/structural integrity of the device.

A schematic of a scramjet engine illustrating its main components is shown in Fig. 1. The supersonic freestream flow is decelerated by a shock system emanating from the vehicle forebody, which also serves to increase the static pressure. To achieve Mach numbers in the hypersonic regime, fuel, and consequently heat, addition in the engine must take place at supersonic flow speeds [1, $]$ ], otherwise, pressure losses and structural stresses render the process inefficient or even impossible. The combustion products are then expanded through a diverging nozzle. Heat release drives local Mach numbers toward sonic and, if enough heat is released, it causes thermal choking and a precombustion pressure rise. An isolator is required to contain this pressure rise and prevent engine unstart [3]. From a cycle-efficiency viewpoint, the air-breathing engine is much superior to other types of chemical-propulsion engines because it uses oxygen from the air $[1,4]$.

Several techniques for fuel injection into supersonic crossflows exist, aimed to enhance mixing and reduce pressure losses in the combustor. These include transverse jets, compression and expansion ramps, steps and cavities, and strut-based injector designs. More detailed discussions of other injection techniques can be found in the reviews of Curran et al., Schetz et al., and Seiner et al. [3, $, \underline{5}, \underline{6}]$. Although designs diverge, common desirable characteristics can be extracted, namely large penetration and rapid mixing, while minimizing pressure losses. The main mechanism for enhancing mixing is the generation of axial vorticity, which acts by exciting instabilities in turbulent shear flows [7]. The aerodynamic ramp injector, or aeroramp, was designed with the preceding considerations in mind. It consists of an array of flush-wall injectors arranged to create vorticity and use jet interaction to enhance mixing and penetration characteristics over those of a single inclined jet [8-10].

Flame holding and flame stabilization are also critical features of a successful hypersonic propulsion system. A low-strain rate region that can trap slow-moving fluid and anchor the flame is required. This is typically achieved by including a subsonic recirculation zone, in 


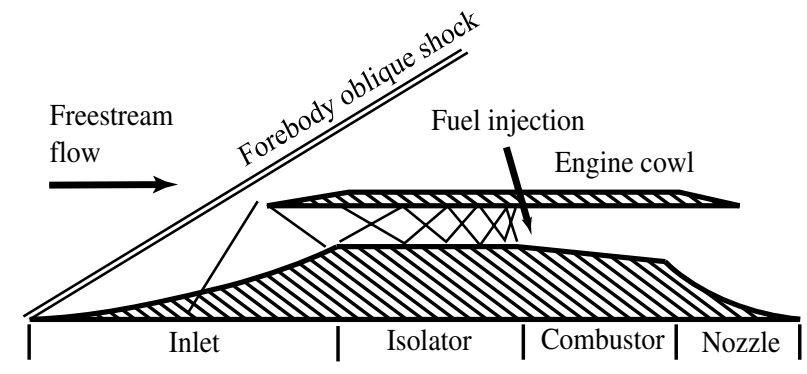

Fig. 1 Schematic of a scramjet engine.

the form of a cavity, or the aft section of a compression ramp. However, such devices have large pressure penalties associated with them, making them less efficient for supersonic combustion applications. The concept of using a plasma torch as an igniter and flame holder has also been investigated [11-13]. A plasma torch is a device in which a flowing gas is passed through an electric arc, producing plasma, i.e., a state in which individual atoms of the medium are ionized but are overall electrically neutral. Plasma contains a rich mixture of various excited species, which aid ignition, making such devices attractive for a wide range of applications, such as flame stabilization, lean burning in internal combustion engines, exhaust emission control, and ignition/combustion applications [14]. Plasma torches vary widely in design, but they are all primarily based on the production of an electric arc to dissociate and ionize a feedstock gas.

The present study demonstrates the performance characteristics of the integrated aeroramp-injector/plasma-torch igniter as a scramjet combustor system and determines its operability limits. The system was tested in a heated Mach 2 crossflow. Hydrogen and ethylene were used as fuels, and wall-static pressure measurements were taken to determine the extent of combustion. This study was the first time the aeroramp and plasma torch have been combined in realistic scramjet flight conditions, without a flame-holding feature such as a cavity, and demonstrated combustion. The successful integration of the two improved the performance of the aeroramp alone and allowed for a wider range of operating conditions to be achieved. A one-dimensional integral simulation code was used to analyze the experimental results and determine air-specific impulse and combustion efficiency.

\section{A. Experimental Hardware}

\section{Experimental Setup}

The integrated aeroramp-injector/plasma-torch igniter was used as the combustor system of a model scramjet engine. The aeroramp was composed of four flush-wall sonic jets, arranged in a two-by-two matrix. The jets were at prescribed transverse (pitch) and toe-in (yaw) angles, as illustrated in Fig. 2 , that were optimized previously [10] to enhance mixing and minimize pressure losses.

Each injector had a diameter of $1.59 \mathrm{~mm}$, and the equivalent diameter was $d_{\mathrm{eq}}=3.18 \mathrm{~mm}$. The equivalent diameter was defined as $d_{\text {eq }}=d_{j} \cdot \sqrt{n}$, where $d_{j}$ is the individual jet diameter and $n$ is the number of injector jets (four here). This corresponds to the diameter of a single injector that would have the same area as the total area of the aeroramp jets. All distances are nondimensionalized by $d_{\mathrm{eq}}$. The jets were spaced by $4 d_{\mathrm{eq}}$ in the streamwise direction and $2 d_{\mathrm{eq}}$ in the cross-stream direction.

A plasma torch was used as the ignition and flame-holding device. The current torch design has evolved from the third generation Virginia Tech plasma-torch design (VTPT-3 [14]). The torch used a copper anode and a hafnium-tipped cathode as electrodes. The plasma torch could be placed at three stations downstream of the aeroramp center, at 6,8 , and $10 d_{\text {eq }}$. Figure $\underline{3}$ shows a schematic of the plasma-torch igniter.

A Thermal Dynamics 100XL Plus welder power supply was used to provide the dc power to the torch. The power supply provided $260 \mathrm{~V} \mathrm{dc}$ (open-circuit) and was capable of operating between 15 and 80 A. A Miller Electric HF-251D-1 high-frequency electric starter
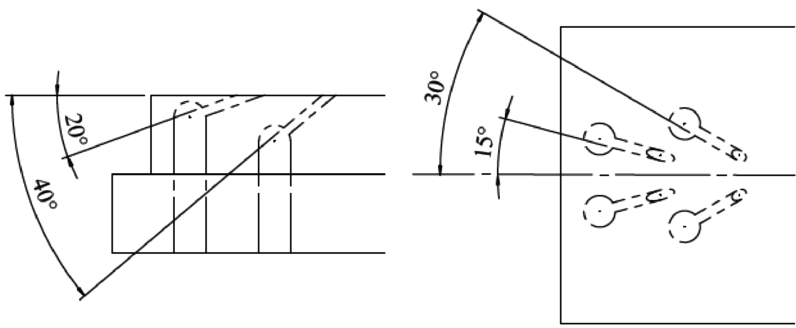

Fig. 2 Schematic of the aeroramp injector.

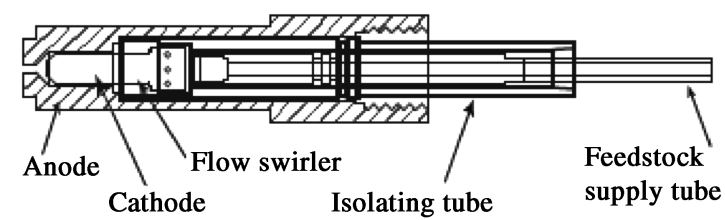

Fig. 3 Schematic of the plasma torch igniter. Its main components and layout can be seen in the diagram.

was used to give a short, high-frequency burst of current to the plasma torch to initiate the electric arc and typically operated for $0.25 \mathrm{~ms}$. The output of the power supply was measured using a $50 \mathrm{~A} / 50 \mathrm{mV}$ shunt and voltage divider/isolator board. The operating voltage of the plasma torch was determined by the gap between the anode and the cathode, and was $120 \mathrm{~V}$. The current was typically adjusted between 25 and 70 A, yielding a torch power $P$ between 3.0 and $8.5 \mathrm{~kW}$.

\section{B. Supersonic Combustion Facility}

Experiments were conducted in the University of Virginia Supersonic Combustion Facility. The overall configuration consisted of an oil-free, two-stage compressor, desiccant air dryers, ballast, and air storage tanks, a 14-stage electrical resistance heater, ceramic flow straightener, supersonic nozzle, constant-area isolator, combustor test section, and exhaust tube. The facility is capable of continuous operation and provided a flow total temperature near $1100 \mathrm{~K}$. The electrical heater provided a hot test gas free of vitiates, such as water, NO, particles, and other radical species $[15,16]$. At Mach 2, the test section static pressure was $42 \mathrm{kPa}$ with a total pressure of $330 \mathrm{kPa}$.

A schematic of the combustion duct is presented in Fig. 4, in which the coordinate system used is also defined with its origin at the center of the aeroramp injector. The flowpath consisted of a Mach 2 nozzle, a constant-area, rectangular isolator, and a rectangular combustion duct. At $x / d_{\text {eq }}=18.9$, the wall opposite the injector wall had a 2.9 deg divergence. The combustion duct maintained a constant area up to the point where the divergence began. The combustor duct extended to $x / d_{\text {eq }}=116.8$ from the injector center, at which point it exited to atmosphere as a freejet. Fuel was introduced to the flow with the aeroramp injector. The primary data obtained from the facility were wall-static pressure measurements, on the wall opposite the injection wall. Table 1 presents detailed dimensions of the combustor configuration.

Fused silica windows provided optical access on two sides of the combustor duct. The windows were located between $x / d_{\text {eq }}=9.9$ and 28.5, and extended from $z / d_{\mathrm{eq}}=2.5$ to 8.0. The Mach 2 nozzle, injector wall, window support frames, and portions of the combustion duct were cooled with internal water passages. The injector wall and the opposite wall, from $x / d_{\text {eq }}=-15.2$ to 52 , were zirconia coated.

\section{Data Acquisition}

Wall-static pressure data were measured through a Setra pressure transducer and a scanning Scanivalve. The scanner operated at an interrogation frequency of approximately $0.5 \mathrm{~Hz}$ and sequentially measured all ports. A complete purge and scan cycle took 


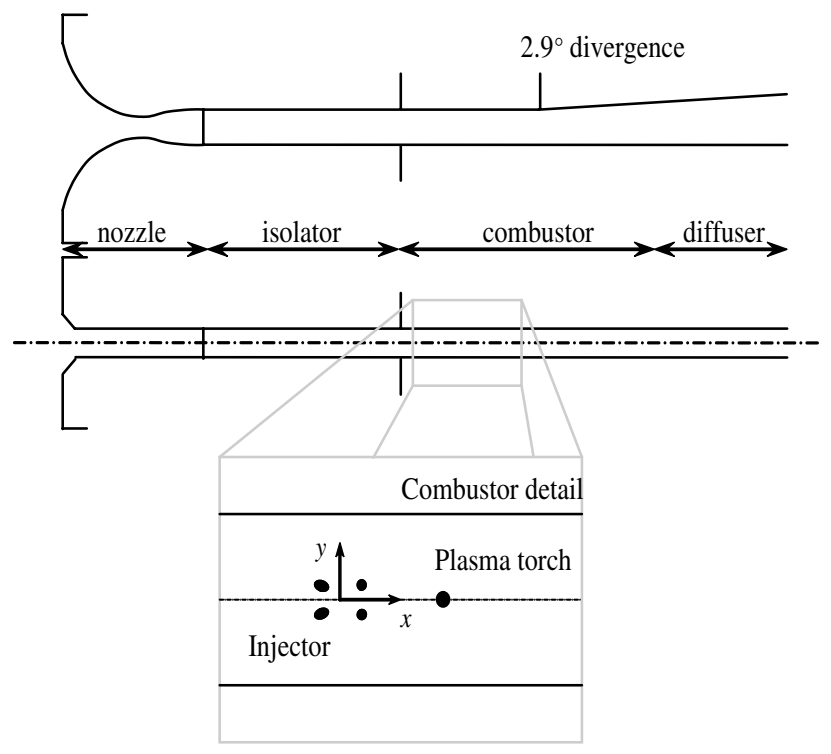

Fig. 4 Schematic of the facility combustor.

approximately $150 \mathrm{~s}$ to complete. Experimental uncertainties of pressure measurements were estimated to be $\pm 2 \%$. The feedstock gas was supplied to the torch through a high-pressure gas cylinder connected to the torch through a Sierra 840 flow controller and Sierra 902C digital dual channel readout. Typical operating flow rates varied between 20 and 40 slpm (standard liters per minute) at pressures of $380-450 \mathrm{kPa}$. The fuel mass flow rate was measured using a Hastings mass flow meter. Quoted equivalence ratios are based on calculated air and measured fuel flow rates.

\section{Results and Discussion}

Combustion experiments were conducted in the direct-connect supersonic facility described in the preceding section. Two gases were used as "fuels," hydrogen $\left(\mathrm{H}_{2}\right)$ and a hydrocarbon, ethylene $\left(\mathrm{C}_{2} \mathrm{H}_{4}\right)$. Hydrogen was selected due to its high reactivity and low ignition delay time, such that an experimental base could be established and performance parameters of the injector/igniter configuration could be established. Hydrocarbon fuels are more practical from an aircraft systems point of view, due to their higher densities and ease of storage compared with hydrogen, and so ethylene was selected as the hydrocarbon fuel to test. Further, a vast amount of experimental data are available for both fuels in the open literature, aiding in comparisons with other work.

Experiments were conducted with both fuels at the highest enthalpy currently available in the facility, corresponding to an air total temperature near $1000 \mathrm{~K}$ and a freestream flight Mach number of $M_{\infty}=4.2$. Subsequently, the integrated aeroramp/plasma-torch configuration was tested at lower enthalpies. The primary data obtained from the facility were wall-static pressure measurements

Table 1 Reference distances and areas of combustor configuration

\begin{tabular}{lcr}
\hline \hline Location & $\mathrm{m}$ & \multicolumn{1}{c}{$d_{\mathrm{eq}}$} \\
\hline Isolator entrance & -0.305 & -95.60 \\
Isolator exit & -0.049 & -15.36 \\
Isolator center & 0.000 & 0.00 \\
Torch "station 2" & 0.025 & 8.00 \\
2.9 deg divergence & 0.060 & 18.88 \\
Combustor exit & 0.371 & 116.8 \\
Combustor width & 0.038 & 10.0 \\
Combustor height & 0.025 & 8.0 \\
Isolator exit area & $0.97 \cdot 10^{-3} \mathrm{~m}^{2}$ \\
Combustor wall area & $29.61 \cdot 10^{-3} \mathrm{~m}^{2}$ \\
Combustor exit area & $1.37 \cdot 10^{-3} \mathrm{~m}^{2}$ \\
\hline \hline
\end{tabular}

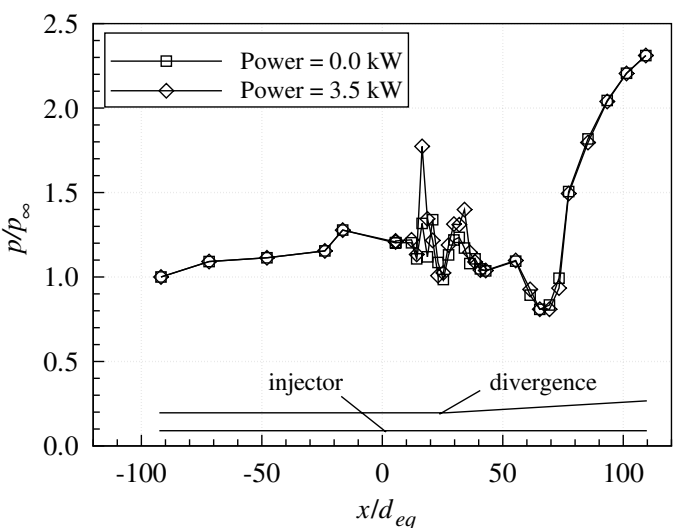

Fig. 5 Effect of torch power on wall pressure measurements (normalized by $p_{\infty}=42 \mathrm{kPa}$ ).

and these results are presented next for each case tested. The pressure rise achieved is used as the metric to establish the presence of combustion.

The experimental sequence for reacting runs is outlined as follows. First, the continuous flow wind tunnel was brought up to the desired steady-state operating conditions. Then, fuel was introduced into the flow at a lean equivalence ratio. The feedstock gas was allowed to flow and the plasma torch was powered on to ignite the fuel-air mixture. The torch power was adjusted until combustion appeared steady. The fueling rate was then fine-tuned to the desired equivalence ratio, and the purge and measurement cycle for the wall pressures was initiated. Fueling rates were gradually increased with the mixture ignited to prevent abrupt pressure rises in the test section.

\section{A. Nonreacting Cases}

Figure 5 presents the normalized wall-static pressure distribution from two nonreacting experiments. The figure shows the measured wall pressures from the facility nozzle exit through the isolator, combustor, and exhaust nozzle for a "tare" condition (fuel off/plasma torch off) and for a case with fuel off and plasma torch operating at $3.8 \mathrm{~kW}$. The mean flow is at a static pressure of $42 \mathrm{kPa}$ and a stagnation temperature of $1000 \mathrm{~K}$. An outline of the flow path is presented underneath the pressure traces to provide a spatial frame of reference.

The tare pressure profiles were fairly constant until $x / d_{\mathrm{eq}}=70$, at which point an oblique-shock train resided in the facility to match the flow with the atmospheric exhaust conditions. Tare pressure profiles were taken for all test conditions and were nearly identical; they are presented in each pressure distribution plot in the subsequent sections for reference. The fluid-dynamic effect of the torch operation on the flow is also seen in this figure. A weak pressure rise is observed at $x / d_{\mathrm{eq}}=15$, where the bow shock off the feedstock plume impinges on the opposing wall. The torch power was compared with the energy released by the exothermic fuel-air reaction in the combustor. It was found that for the leanest fueling conditions, i.e., for $\phi=0.08$ (assuming 100\% combustion efficiency), the torch power was less than $10 \%$ of the energy released by the reaction each second. As fueling rates increased, this percentage decreased further. It is clear that the heat deposited to the flow from the torch had no significant effect and was insufficient to cause thermal choking.

\section{B. Hydrogen Fuel Experiments}

Experiments were conducted with hydrogen fuel injected through the aeroramp at various total pressures and a total temperature of $290 \mathrm{~K}$. The plasma torch was located at station $2\left(x / d_{\mathrm{eq}}=8\right)$. The feedstock gas was nitrogen flowing at $40 \mathrm{slpm}$, and the average plasma torch power was $3.5 \mathrm{~kW}$. A range of global equivalence ratios was tested $0.08 \leq \phi \leq 0.32$, with corresponding jet-to-freestream momentum flux ratios of $0.5 \leq \bar{q} \leq 2$. Detailed experimental conditions are presented in Table $\mathrm{A} 1$ in the Appendix. 


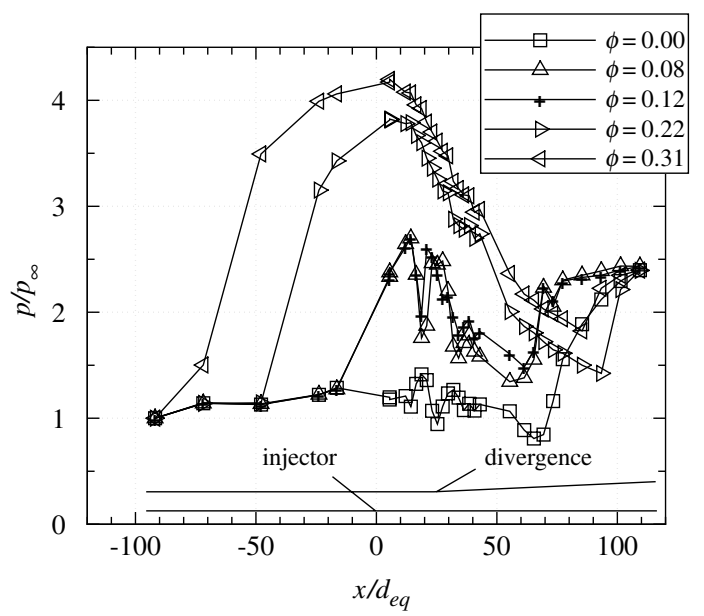

Fig. 6 Effect of torch power on wall pressure measurements (normalized by $p_{\infty}=42 \mathrm{kPa}$ ).

Wall-static pressure profiles throughout the combustor length are presented in Fig. 6, at several different global equivalence ratios. For $\phi<0.12$, the maximum pressure rise generated in the combustor is about 2.7, and the flow remains supersonic throughout the duct. This result is in good agreement with a Rayleigh line analysis of the flow, which indicates that a pressure rise of at least 2.8 is required to thermally choke the flow. As the fuel mass flow rate is increased, the pressures increase in the isolator and the combustor. A normal-shock train system is established in the isolator, which moves progressively more upstream at higher equivalence ratios. The combustion has transitioned to a subsonic mode, illustrating the dual-mode operation of the combustor. A peak pressure rise of 4.2 is recorded in the combustor. The facility was designed to achieve a maximum pressure ratio between the isolator inlet and exit [17], i.e., the normalshock pressure rise, which is 4.5 at Mach 2.

Similar data for hydrogen combustion are readily available in the literature. Specifically, the experiments of Le et al. [17] were conducted in the same facility under the same total pressure and temperature conditions, with the exception of the fuel injection system, which used an unswept $10 \mathrm{deg}$ compression ramp with a $M=1.7$ conical nozzle. The range of equivalence ratios tested in the present study overlaps with that of Le et al., and the data for both cases were compared elsewhere and correlate very well [18], i.e., the maximum pressure rise achieved and the location of the precombustion shock train are in good agreement for both the aeroramp and the physical ramp experiments. However, in the present study, the integrated aeroramp-injector/plasma-torch igniter system provide a flush-wall configuration that minimizes total pressure losses in the combustor and thus maximizes the thrust of the device (see discussion in [18]).

\section{Ethylene Fuel Experiments}

The same injector geometry was tested with a hydrocarbon fuel, ethylene $\left[\mathrm{C}_{2} \mathrm{H}_{4}\right]$, also injected at a total temperature of $290 \mathrm{~K}$. Both supersonic and subsonic (dual-mode) combustion were demonstrated over a range of equivalence ratios of $0.14 \leq \phi \leq 0.48$ with ethylene fuel. The corresponding range of jet-to-freestream momentum flux ratio was between 0.6 and 1.8. The plasma torch was located at station $3\left(x / d_{\text {eq }}=10\right)$, the feedstock gas was air flowing at $40 \mathrm{slpm}$, and the average power to the torch was $6.1 \mathrm{~kW}$. Detailed experimental conditions are presented in Table A2 in the Appendix. The position of the plasma torch was selected based on preliminary cold-flow studies with ethylene fuel, which indicated that station 3 yielded an equal emission plume size as station 2, however, allowed for a longer fuel-mixing time, thus reducing the mean composition at the location of the torch and providing a more ignitable mixture (see [19] and discussion therein). Air was chosen as the feedstock because previous studies have proven that it is a more effective feedstock for hydrocarbon fuels $[\underline{19}, \underline{20}]$. Higher torch

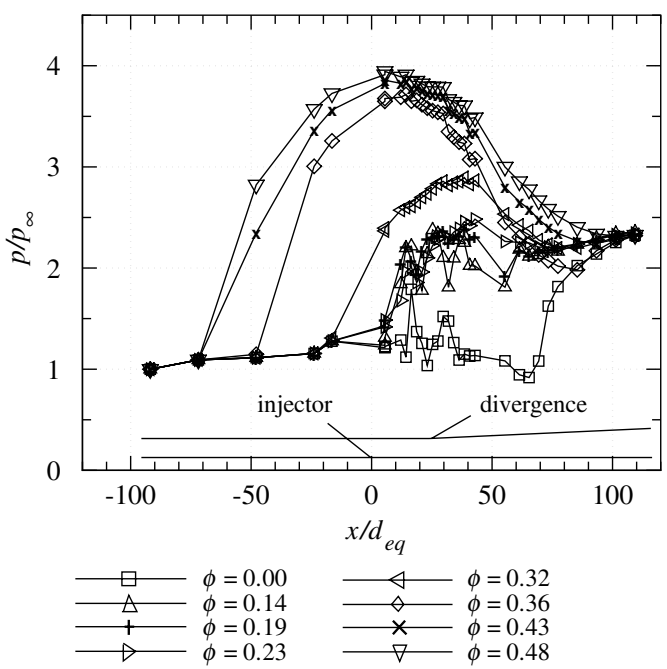

Fig. 7 Ethylene combustion: isolator/combustor pressure traces. Wallstatic pressure normalized by isolator inlet static pressure $\left(p_{\infty}=42 \mathrm{kPa}\right)$.

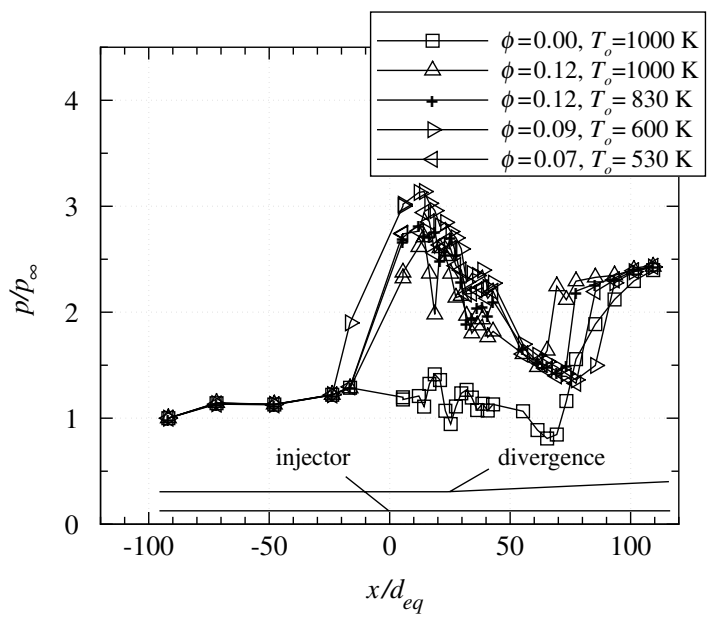

Fig. 8 Hydrogen combustion, temperature variation study: isolator/ combustor pressure traces. Wall-static pressure normalized by isolator inlet static pressure $\left(p_{\infty}=42 \mathrm{kPa}\right)$.

powers were required to create local conditions that would favor ignition, because the unaided ignition delay times of the two fuels used (hydrogen and ethylene) differ by an order of magnitude [21].

Normalized wall-static pressure distributions are presented in Fig. 7. As with hydrogen fuel, transition from the pure scram mode to the dual-mode ramjet is achieved. From the expected pressure rise ratio predicted by the Rayleigh flow, and from inspection of the pressure profiles, the transition equivalence ratio is approximately $\phi \approx 0.32$, where the combustor can again sustain a maximum pressure rise ratio of approximately 2.8. The maximum wall pressure ratio rise obtained for the highest equivalence ratio was 4 , again close to the normal-shock pressure rise.

\section{Air Total Temperature Variation Study}

In an attempt to investigate the off-design performance of the scramjet combustor model, the facility air total temperature was varied. Aside from the aforementioned design conditions at $T_{o}=1000 \mathrm{~K}$, air total temperatures considered were 820,610 , and $530 \mathrm{~K}$ for hydrogen, and 830 and $680 \mathrm{~K}$ for ethylene. Fuel total temperatures were maintained at $290 \mathrm{~K}$. The range of equivalence ratios tested was not as wide as for the design conditions, however, both supersonic and dual-mode combustion were established at all temperatures. Wall-static pressure profiles demonstrating supersonic combustion are shown in Figs. $\underline{8}$ and $\underline{9}$, for hydrogen and ethylene 


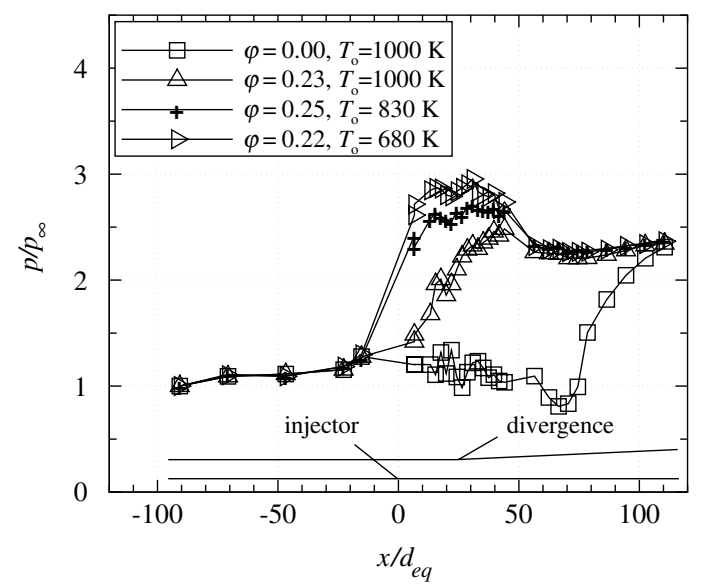

Fig. 9 Ethylene combustion, temperature variation study: isolator/ combustor pressure traces. Wall-static pressure normalized by isolator inlet static pressure $\left(p_{\infty}=42 \mathrm{kPa}\right)$.

fuels, respectively. Note that as the total temperature was decreased, less heat release was required to produce thermally choked flow and so the corresponding equivalence ratio was decreased.

The lower temperature limit of $530 \mathrm{~K}$ in the hydrogen experiments was imposed from facility limitations, as a sufficient flow rate could not be provided while maintaining a constant total pressure. For the ethylene experiments, the operational lifespan of the torch proved the limiting factor. Runs were performed initially at the highest possible total temperature and subsequently the temperature was decreased. Constant reignition of the torch and the relatively long operating times eroded the anode to such a degree that further ignitions were impossible. The anode failure occurred at $680 \mathrm{~K}$. Because the temperature variation study with ethylene fuel was beyond the scope of this work, further experiments were not pursued, however, the authors anticipate that ignition of ethylene at even lower temperatures may be possible.

The ethylene combustion experiments performed here explore similar flight conditions as those in the experiments of Mathur et al. [22]. Mathur et al. employed low-angle jet injection coupled with a cavity flame-holder in a continuous, supersonic, direct-connect, vitiated-air, combustion facility. Fuel could be introduced through the cavity base as well. To achieve off-design operating conditions, Mathur et al. varied the tunnel temperature, but found that "with room-temperature ethylene, ignition and combustion did not occur at facility stagnation temperatures below $1222 \mathrm{~K}$." The integration of an ignition device in the form of a plasma torch, with the fuel injection system, significantly widens the range of feasible operating conditions, and proves the robustness of the system, even under a harsh supersonic flow environment with relatively low temperatures.

\section{Performance Analysis}

Quantitative data obtained in this study were limited to wall-static pressures. To deduce other flow properties and engine characteristics, such as combustion efficiency and specific impulse, from these pressure distributions, the Ramjet Performance Analysis code (RJPA) was used [23,24]. RJPA is a one-dimensional, integral simulation code that uses convenient control volumes to define each component of the engine. Each of these components (freestream, diffuser, combustor, exit nozzle) is analyzed separately with some

Table 2 Flight conditions for experimentally tested cases

\begin{tabular}{lcccc}
\hline \hline$T_{o}, \mathrm{~K}$ & 1000 & 820 & 610 & 530 \\
\hline$M,-$ & 4.22 & 3.67 & 3.01 & 2.67 \\
$h, \mathrm{~km}$ & 26.8 & 22.3 & 16.2 & 13.1 \\
$A_{\text {inlet }} \cdot 10^{3} \mathrm{~m}^{2}$ & 6.22 & 3.94 & 2.18 & 1.63 \\
$A_{\text {inlet }} / A_{\text {comb }},-$ & 6.43 & 4.07 & 2.25 & 1.67 \\
\hline \hline
\end{tabular}
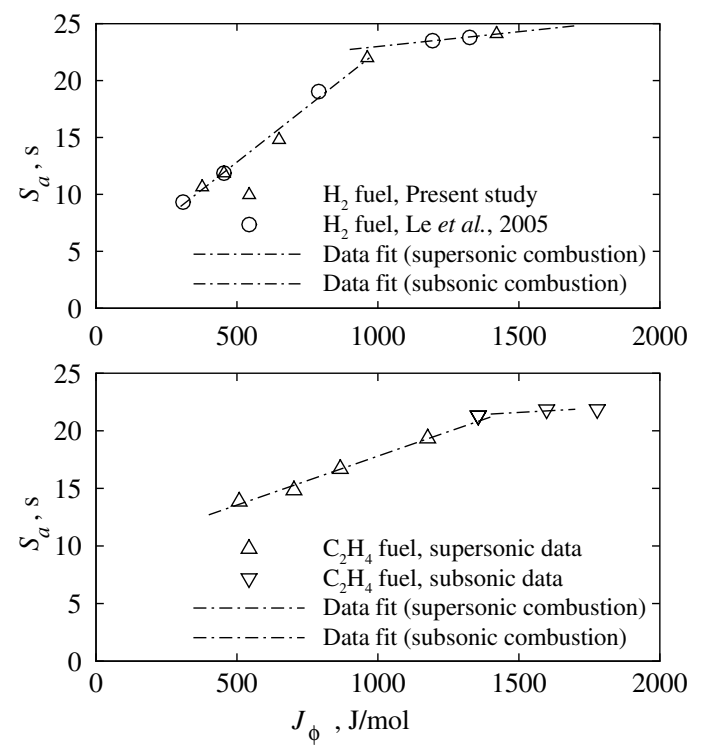

Fig. 10 Air-specific impulse (seconds). Subsonic and supersonic combustion regimes are indicated on the graph.

combination of experimental data and analytical modeling (heat addition into duct with friction). This approach allows the program to find exit conditions that satisfy the integral conservation equations, the equation of state, and certain empirical models [25].

For this analysis, a virtual inlet and nozzle were assumed such that thrust results could be obtained. The base case experimental operating conditions correspond to "flight conditions" of $M_{\infty}=4.2$ at $27 \mathrm{~km}$. The assumed inlet had a kinetic efficiency of $98 \%$ and the nozzle expanded to the freestream static pressure, also with $98 \%$ efficiency. The combustor inlet and exit stations were selected at $x / d_{\mathrm{eq}}=-15.2$ and 56.5 , respectively. Note that, at the exit station, the combustor area is $1 \cdot 10^{-3} \mathrm{~m}^{2}$. These values were selected based on the locations of pressure taps in the facility and in such a way that the influence of the shock in the exhaust duct due to atmospheric exhaust would not be reflected in the pressure measurements.

Table 2 presents the simulated flight conditions, namely flight Mach number, altitude, assumed inlet area, and inlet-to-combustor area ratio for each total temperature tested. These conditions were used as inputs to RJPA, such that the isolator entrance pressure, temperature, and area were matched. Further, the global equivalence ratio for each run was also specified. The combustion efficiency was then iterated over, until the maximum (calculated) pressure in the combustor matched the experimental data. With the iterations converged, performance data could be extracted from the onedimensional simulation model.

The thrust results are presented in the form of air-specific impulse, defined as

$$
S_{a}=\frac{F}{\dot{m}_{\text {fuel }}+\dot{m}_{\text {air }}}
$$

The air-specific impulse results were plotted against the product of equivalence ratio multiplied by the stoichiometric fuel-to-air ratio times the fuel heating value, or $J_{\phi}$, and are presented in Fig. 10 . The heating value of a substance is defined as the amount of heat released during the combustion of a specific amount of the substance. This product tends to correlate curves for different fuels. Air-specific impulse was chosen as the metric of comparison because, for airbreathing engines, the quantity of interest is the amount of thrust per total mass flux through the engine.

The hydrogen combustion data set was augmented with data by Le et al. [17]. These data were obtained in the same facility at the same operating conditions (i.e., total pressure and temperature), but with the fuel injected through a physical $10 \mathrm{deg}$ unswept compression ramp with a Mach 1.7 conical nozzle. The data are compared elsewhere [18] and are found to correlate very well with the aeroramp 

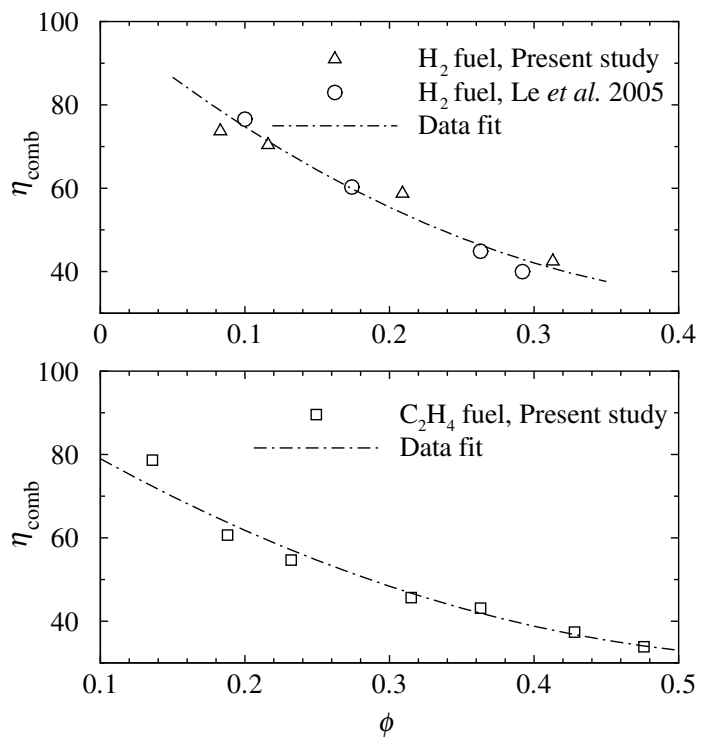

Fig. 11 Combustion efficiency as a function of global equivalence ratio.

injector, indicating that the same performance can be obtained with the aeroramp injector without suffering the pressure losses associated with a physical ramp injector.

The transition from supersonic to dual-mode subsonic combustion occurs around $1000 \mathrm{~J} / \mathrm{mol}$ for hydrogen and $1300 \mathrm{~J} / \mathrm{mol}$ for ethylene. Each region displays a different thrust (and, consequently, air-specific impulse) characteristic. The supersonic combustion region is dominated by a linear relation between thrust and equivalence ratio; as fuel flow rates are increased, more thrust is produced. However, once the duct becomes thermally choked, the thrust reaches an almost constant plateau, with slight additional benefit gained from further increase in the equivalence ratio. The additional contribution to the thrust comes from the momentum of the fuel stream (due to the angled injection), something realized in RJPA by the increase of mass flux through the duct with increasing equivalence ratio.

A second useful result computed by RJPA was the combustion efficiency. Combustion efficiencies for hydrogen and ethylene at the baseline case of $T_{o}=1000 \mathrm{~K}$ are presented in Fig. 11. The quadratic functions

$$
\begin{gathered}
\eta_{H 2}(\phi)=297.3 \phi^{2}-282.3 \phi+100 \\
\eta_{C 2 H 4}(\phi)=190.3 \phi^{2}-229.1 \phi+100
\end{gathered}
$$

were fit to the hydrogen and ethylene data sets, respectively, and were found to capture the trend in combustion efficiency as a function of equivalence ratio. As a definition, the fits were forced to intercept the efficiency axis at $100 \%$ for $\phi=0$. Again, the supersonic combustion region was found to display more rapid changes in combustion efficiency with increasing equivalence ratio, however, in the subsonic combustion regime, a minimum in efficiency was asymptotically approached.

\section{Conclusions}

Supersonic combustion experiments were conducted in a highenthalpy, direct-connect facility, simulating flight of a dual-mode combustion scramjet at $M_{\infty}=4.2$ at $27 \mathrm{~km}$. An integrated aerodynamic ramp-injector/plasma-torch igniter was used as the combustion system and hydrogen and ethylene were used as fuels. The system demonstrated favorable ignition and flame-holding characteristics in the Mach 2 crossflow. These experiments were the first time this geometry was successfully tested in a flow simulating scramjet flight conditions, validating the idea of a flush-wall/ minimum-pressure-loss injection and ignition system.
Supersonic and dual-mode subsonic combustion were demonstrated over a range of global equivalence ratios and the operability limits of the device were found to be $0.08 \leq \phi \leq 0.31$ for hydrogen and $0.13 \leq \phi \leq 0.48$ for ethylene. The air total temperature was varied to evaluate the performance of the combustion system at offdesign conditions. Steady supersonic combustion was established at total temperatures as low as 530 and $680 \mathrm{~K}$ for hydrogen and ethylene, respectively, demonstrating the robustness of the plasma torch as an igniter in supersonic crossflows. The data correspond to a range of flight Mach numbers, $2.7 \leq M_{\infty} \leq 4.2$. A one-dimensional integral simulation code (RJPA) was used to compute specific impulse and combustion efficiency from the experimental data. Air-specific impulse was found to reach a peak after the transition from supersonic to dual-mode combustion; additional increases in fuel flow rates provided minor increases in the thrust of the device. The combustion efficiency was found to be a quadratic function of equivalence ratio for both fuels. Combustion efficiencies varied from 40 to $80 \%$, with the supersonic combustion regime being more efficient.

\section{Appendix: Detailed Experimental Conditions}

Tables $\mathrm{A} 1$ and $\mathrm{A} 2$ present the detailed experimental conditions for the hydrogen and ethylene runs described in the text, respectively. Note that in all cases, the fuel total temperature was held constant to $290 \mathrm{~K}$, and the tunnel total pressure $333 \pm 1 \mathrm{kPa}$, which corresponds to an air mass flow rate of $0.24 \mathrm{~kg} / \mathrm{s}$ at $T_{o}=1000 \mathrm{~K}$.

Table A1 Experiments with hydrogen fuel, plasma torch in station 2 with $\mathrm{N}_{2}$ feedstock

\begin{tabular}{ccccccc}
\hline \hline$T_{o}, \mathrm{~K}$ & $\dot{m}_{\text {fuel }}, \mathrm{g} / \mathrm{s}$ & $\phi$ & $P, \mathrm{~W}$ & $\bar{q}$ & $S_{a}, \mathrm{~s}$ & $\eta_{\text {comb }}$ \\
\hline 1010 & - & 0 & 0 & $\overline{0}$ & $\overline{10.6}$ & $\overline{73.7 \%}$ \\
1014 & 0.5 & 0.08 & 3300 & 0.57 & 10.6 & $70.4 \%$ \\
1020 & 0.7 & 0.12 & 3500 & 0.77 & 11.9 & $58.7 \%$ \\
1010 & 1.2 & 0.22 & 3200 & 1.31 & 22.0 & $5.5 \%$ \\
1012 & 1.8 & 0.31 & 3200 & 1.92 & 24.1 & $42.5 \%$ \\
\hline \hline
\end{tabular}

Table A2 Experiments with ethylene fuel, plasma torch in station 3 with air feedstock

\begin{tabular}{lcccccc}
\hline \hline$T_{o}, \mathrm{~K}$ & $\dot{m}_{\text {fuel }}, \mathrm{g} / \mathrm{s}$ & $\phi$ & $P, \mathrm{~W}$ & $\bar{q}$ & $S_{a}, \mathrm{~s}$ & $\eta_{\text {comb }}$ \\
\hline 1000 & - & 0 & 0 & $\bar{n}$ & $\overline{1}$ & $\overline{78.7 \%}$ \\
1000 & 1.9 & 0.14 & 5500 & 0.58 & 13.9 & 7.8 \\
1001 & 2.6 & 0.19 & 6500 & 0.76 & 14.8 & $60.7 \%$ \\
1001 & 3.2 & 0.23 & 6400 & 0.86 & 16.7 & $54.7 \%$ \\
1001 & 4.4 & 0.32 & 6500 & 1.18 & 19.3 & $45.7 \%$ \\
1001 & 5.0 & 0.36 & 7000 & 1.35 & 21.3 & $43.1 \%$ \\
1001 & 5.9 & 0.43 & 7100 & 1.60 & 21.8 & $37.4 \%$ \\
1002 & 6.6 & 0.48 & 7400 & 1.77 & 21.9 & $33.9 \%$ \\
\hline \hline
\end{tabular}

\section{Acknowledgments}

This research was supported by the NASA Langley Research Center under Grant NAG-1-02108. The authors would like to acknowledge the help of L. Jacobsen in the design of the plasma torch and the help of R. Krauss in the operation of the supersonic combustion facility.

\section{References}

[1] Ferri, A., "Mixing-Controlled Supersonic Combustion," Annual Review of Fluid Mechanics, Vol. 5, 1973, pp. 301-338. doi:10.1146/annurev.fl.05.010173.001505

[2] Billig, F. S., "Research on Supersonic Combustion," Journal of Propulsion and Power, Vol. 9, No. 4, 1993, pp. 499-514.

[3] Curran, E. T., Heiser, W. H., and Pratt, D. T., "Fluid Phenomena in Scramjet Combustion Systems," Annual Review of Fluid Mechanics, Vol. 28, 1996, pp. 323-360. doi:10.1146/annurev.fl.28.010196.001543 
[4] Fry, R. S., "A Century of Ramjet Propulsion Technology Evolution," Journal of Propulsion and Power, Vol. 20, No. 1, 2004, pp. 27-58.

[5] Schetz, J. A., Thomas, R. H., and Billig, F. S., "Mixing of Transverse Jets and Wall Jets in Supersonic Flow," International Union of Theoretical and Applied Mechanics (IUTAM) Symposium on Separated Flows and Jets, Springer-Verlag, New York, Feb. 1992.

[6] Seiner, J. M., Dash, S. M., and Kenzakowski, D. C., "Historical Survey on Enhanced Mixing in Scramjet Engines," Journal of Propulsion and Power, Vol. 17, No. 6, 2001, pp. 1273-1286.

[7] Dimotakis, P. E., "Turbulent Free Shear Layer Mixing and Combustion," High-Speed Propulsion Systems, edited by S. N. B. Murthy and E. T. Curran, Vol. 137, Progress in Astronautics and Aeronautics, AIAA, Washington, DC, 1991, pp. 265-340.

[8] Cox-Stouffer, S. K., Fuller, R. P., Schetz, J. A., and Walters, R. W., "Vortical Interactions Generated by an Injector Array to Enhance Mixing in Supersonic Flow," AIAA Paper 1994-0708, 1994.

[9] Fuller, R. P., Wu, P. K., Nejad, A. S., and Schetz, J. A., "Comparison of Physical and Aerodynamic Ramps as Fuel Injectors in Supersonic Flow," Journal of Propulsion and Power, Vol. 14, No. 2, 1998, pp. 135-145.

[10] Jacobsen, L. S., Gallimore, S. D., Schetz, J. A., O’Brien, W. F., and Goss, L. P., "Improved Aerodynamic-Ramp Injector in Supersonic Flow," Journal of Propulsion and Power, Vol. 19, No. 4, 2003, pp. 663-673.

[11] Chen, D. C., Lawton, J., and Weinberg, F. J., "Augmenting Flames with Electric Discharges," Proceedings of the 10th Symposium (International) on Combustion, Combustion Inst., Pittsburgh, PA, 1965, pp. 743-754.

[12] Wagner, T. C., O'Brien, W. F., Northam, G. B., and Eggers, J. M., "Plasma Torch Igniter for Scramjets," Journal of Propulsion and Power, Vol. 5, No. 5, 1989, pp. 548-554.

[13] Kitagawa, T., Moriwaki, A., Murakami, K., Takita, K., and Masuya, G., "Ignition Characteristics of Methane and Hydrogen Using a Plasma Torch in Supersonic Flow," Journal of Propulsion and Power, Vol. 19, No. 5, 2003, pp. 853-858.

[14] Gallimore, S. D., Jacobsen, L. S., O'Brien, W. F., and Schetz, J. A., "Operational Sensitivities of an Integrated Scramjet Ignition/FuelInjection System," Journal of Propulsion and Power, Vol. 19, No. 2, 2003, pp. 183-189.

[15] Krauss, R. H., McDaniel, J. C., Scott, J. E., Whitehurst, R. B., Segal, C.,
Mahoney, G. T., and Childers, J. M., "Unique, Clean-Air, Continuous Flow, High-Stagnation Temperature Facility for Supersonic Combustion Research," AIAA Paper 1988-3509, 1988.

[16] Krauss, R. H., and McDaniel, J. C., "A Clean Air Continuous Flow Propulsion Facility," AIAA Paper 1992-3912, 1992.

[17] Le, D. B., Goyne, C. P., Krauss, R. H., and McDaniel, J. C., "Experimental Study of a Dual-Mode Scramjet Isolator," AIAA Paper 2005-23, 2005.

[18] Bonanos, A. M., Schetz, J. A., O'Brien, W. F., and Goyne, C. P., "Supersonic Combustion Experiments with a Cavity-Based Fuel Injector," AIAA Paper 2005-3425, 2005.

[19] Jacobsen, L. S., Gallimore, S. D., Schetz, J. A., and O'Brien, W. F., "Integration of an Aeroramp Injector/Plasma Igniter for Hydrocarbon Scramjets," Journal of Propulsion and Power, Vol. 19, No. 2, 2003, pp. $170-182$.

[20] Shuzenji, K., and Tachibana, T., "Superiority of Oxygen as Feedstock for a Plasma Jet Igniter in Supersonic Methane Air Streams," Proceedings of the Combustion Institute, Vol. 29, No. 1, 2002, pp. 875881 . doi:10.1016/S1540-7489(02)80112-2

[21] Colket, M. B., and Spadaccini, L. J., "Scramjet Fuels Autoignition Study," Journal of Propulsion and Power, Vol. 17, No. 2, 2001, pp. 315-323.

[22] Mathur, T., Gruber, M., Jackson, K., Donbar, J., Donaldson, W., Jackson, T., and Billig, F., "Supersonic Combustion Experiments with a Cavity-Based Fuel Injector," Journal of Propulsion and Power, Vol. 17, No. 6, 2001, pp. 1305-1312.

[23] Ramjet Performance Analysis Code (RJPA), "Ramjet Performance Analysis," Applied Physics Lab., Johns Hopkins Univ., Laurel, MD, 1993.

[24] Pandolfini, P. P., Billig, F. S., Corpening, G. P., Corda, S., and Friedman, M. A., "Analyzing Hypersonic Engines Using the Ramjet Performance Analysis Code," APL Technical Review, Vol. 2, No. 1, 1990.

[25] Pandolfini, P. P., and Friedman, M. A., "Instructions for Using Ramjet Performance Analysis (RJPA) IBM-PC Ver. 1.24,” Applied Physics Lab., Johns Hopkins Univ. AL-92-P175, 1992.

L. Maurice Associate Editor 